\title{
Quality by Design and Process Analytical Technology: Important Tools for Buliding Quality in Pharmaceutical Products
}

\author{
Ashrani Sunil*1, Goyal Anju² and Vaishnav Rajat ${ }^{2}$ \\ ${ }^{1}$ M Pharma Research Scholar, Bhupal Nobles' University, India \\ 2Department of Pharmaceutical Quality Assurance, Bhupal Nobles' University, India
}

Received: January 18, 2018; Published: January 30, 2018

*Corresponding author: Sunil Ashrani, M. Pharma Research Scholar, Bhupal Nobles' University, Sewashram Choraya, Udaipur, Rajastan, India, Tel: 7425839345; Email: sunilashrani93@gmail.com

\begin{abstract}
ICH Q8 guideline defines Quality by Design as “a systematic approach to development that begins with predefined objectives and emphasizes product and process understanding and process control, based on sound science and quality risk management. The QbD based approaches provides a high degree of assurance that pharmaceutical manufacturing process is adjustable within a design space and hence the process is robust and managed with a control strategy developed using modern statistical process control methods. It enables a lifecycle approach to validation/continuous process verification. The building of Quality into the manufacturing products at its design stage is very important to reduce expenditure, time \& energy. Also the market recall of products due to batch failure is reduced to minimum with the use of QbD. PAT is also related to QbD. It refers to Process analytical technology. PAT has been defined as "A system for designing, analyzing, and controlling manufacturing through measurements, during processing of critical quality and performance attributes of raw and in-process materials and processes, with the goal of ensuring final product quality". The present paper deals on these two terms QbD and PAT.
\end{abstract}

Keywords: Quality by Design; PAT; Design Stage; ICH Q8

\section{Introduction}

On looking to the scenario in pharmaceutical industries we find that since past few decades, pharmaceutical companies had been spending very large amount of resources to built quality, achieve regulatory compliance, and produce drugs as cost effectively as possible. For this they employ advance processes and technologies. But such efforts have not been so effective. It is due to the of lack of comprehensive, rationale based understanding of these processes, associated critical variables and strategies to control these variables, which is important in assuring quality of the product. The companies show less interest in identifying the root Table 1: Differences between current approach and QbD approach [5].

\begin{tabular}{|c|c|}
\hline Current Approach & QbD Approach \\
\hline Quality is assured by testing and inspection. & $\begin{array}{l}\text { Quality is built into product \& process by design and based on scientific } \\
\text { understanding. }\end{array}$ \\
\hline $\begin{array}{l}\text { It includes only data intensive submission which includes disjointed } \\
\text { information without "big picture". }\end{array}$ & $\begin{array}{l}\text { It includes Knowledge rich submission which shows product knowledge \& } \\
\text { process understanding. }\end{array}$ \\
\hline Here, any specifications are based on batch history. & Here, any specifications based on product performance requirements. \\
\hline Here there is "Frozen process," which always discourages changes. & $\begin{array}{l}\text { Here there is Flexible process within design space which allows } \\
\text { continuous improvement. }\end{array}$ \\
\hline It focuses on reproducibility which often avoids or ignores variation. & It focuses on robustness which understands and control variation \\
\hline
\end{tabular}

cause of manufacturing failures. Furthermore, no rationale-based approach is followed to predict the effects of scale-up on the final product [1]. But with changing time and increasing complexity of regulatory requirements in the approval of a drug to come in market, companies are focusing on methods through which they can prepare a design of the product and do researches related to complexities that may have to be faced in future and thus find out the solutions prior to manufacturing. This study is done through various tools like QbD, PAT etc. The main reason behind is only one and that is to reduce the cost of manufacturing defects (Table 1). tt focuses on reproducibility which often avoids or ignores variation. 


\section{Quality by Design}

The improvement in increasing order without any strategy may not always give positive fruitful results. It would only have little effect on overall process performance or quality. Thus to assure the quality of the product, a more realistic approach is provided by QbD. QbD (Quality by Design) is defined in the ICH Q8 guideline as "a systematic approach to development that begins with predefined objectives and emphasizes product and process understanding and process control, based on sound science and quality risk management" [2,3]. The ideal QbD-based pharmaceutical development effort involves a systematic method relating mechanistic understanding of input material attributes and process parameters to drug product critical quality attributes. Such a development efforts are possible through the use of multivariate experiments that involve modern process controls and enables process understanding (Figures 1 \& 2). QbD identifies parameters that are critical to quality from the perspective of patients, translates them into the attributes that the drug product must possess, and also establishes how the critical process parameters can be changed to consistently produce a drug product having the desired characteristics $[4,5]$.

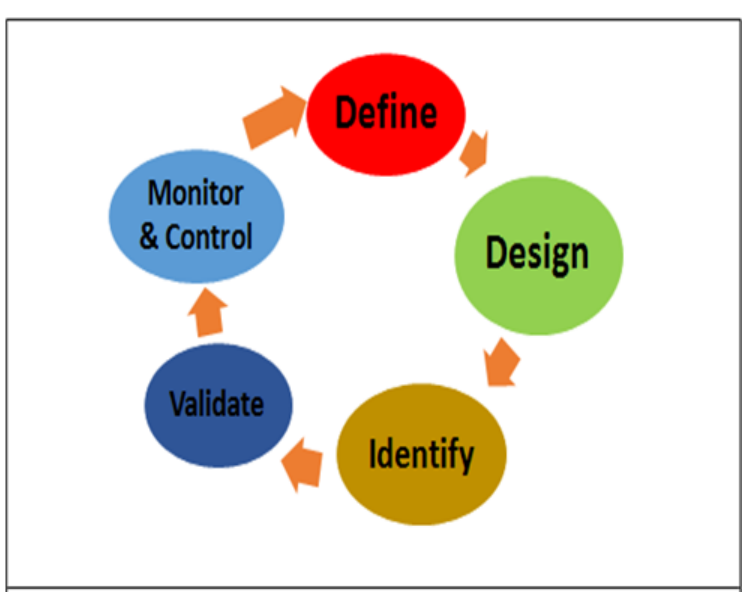

Figure 1: Illustration of the different steps in development of a pharmaceutical product.

Pharmaceutical Quality by Design [3].

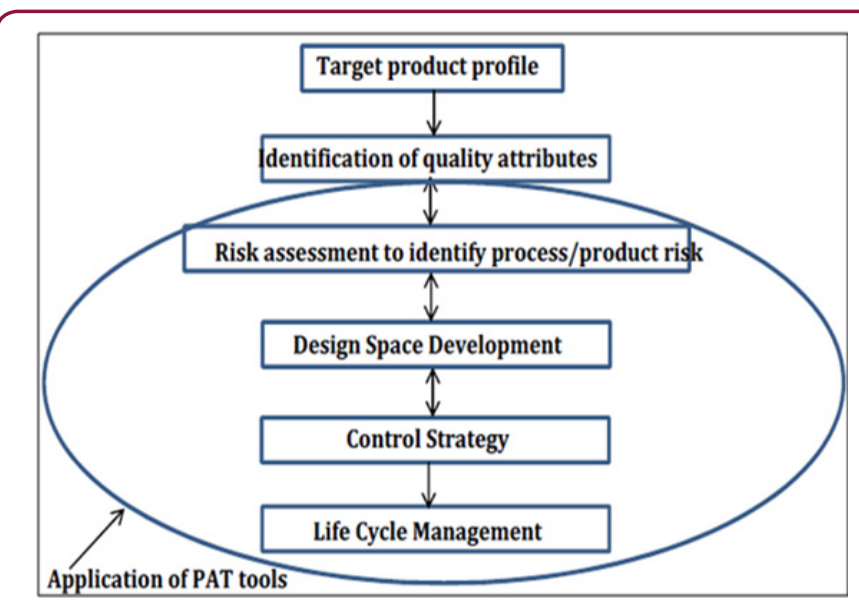

Figure 2: Elements of Quality by Design [8].

\section{Advantages of Adopting Quality by Design Approach [6]}

\section{For industry}

a) It helps in better understanding of the process.

b) It reduces batch failure.

c) It ensures better design of products with fewer problems in manufacturing.

d) It allows for continuous improvement in products \& manufacturing process.

\section{For FDA}

a) It enhances scientific base for analysis.

b) It provides better consistency.

c) It provides more flexibility in decision making.

d) It ensures decisions are made on scientific base \& not on observed information.

\section{A QBD DEVELOPMENT PROCESS MAY INCLUDE [7]}

a. It is started with a target product profile that illustrates the use, safety and efficacy of the product

b. Then, introduces a target product quality profile that the formulators and process engineers use as a quantitative surrogate for aspects of clinical safety and efficacy of the product during development.

c. The collection of relevant prior knowledge about the drug substance, potential excipients and process operations into a knowledge space is also done.

d. Application of risk assessment tools to prioritize knowledge gaps for further investigation is necessary.

e. Formulation of a design to find the critical material (quality) attributes of the final product that is necessary to be controlled to meet the target product quality profile is then done.

f. Also formulate the design of manufacturing process to produce a final product having the required critical materials attributes.

g. Find out the critical process parameters and raw material attributes that should be controlled to achieve these critical material attributes of the final product.

h. Risk assessment must be used to prioritize process parameters and material attributes for experimental verification.

i. Combination of prior knowledge with experiments is important to establish a design space or other representation of process understanding.

j. Making of a control strategy for the entire process that must include raw material controls, process controls and 
monitors, design spaces around individual or multiple unit operations, and/or final product tests.

k. The control strategy must encompass expected changes in scale and can be guided by a risk assessment.

l. Monitoring and update of the process to assure consistent quality continually.

\section{The Target Product Quality Profile (TPQP)}

TPQP has been defined as a "prospective and dynamic summary of the quality characteristics of a drug product that ideally will be achieved to ensure that the desired quality, and thus the safety and efficacy, of a drug product is realized". It covers dosage form and route of administration, dosage form strength(s), therapeutic moiety release or delivery and pharmacokinetic characteristics (e.g., dissolution and aerodynamic performance) appropriate to the drug product dosage form being developed and drug productquality criteria (e.g. sterility and purity) appropriate for the intended marketed product [8].

TPP forms the basis for product design in the following way [9].
a. Dosage form
b. Route of administration
c. Strength, maximum and minimum
d. Release/delivery of the drug
e. Pharmacological characteristic
f. Drug product quality criteria
g. Pharmaceutical elegance

\section{Critical Quality Attributes (CQAS)}

A CQA has been defined as "a physical, chemical, biological or microbiological property or characteristics that should be within an appropriate limit, range, or distribution to ensure the desired product quality." According to ICHQ9 the Identification of CQAs is done through risk assessment. Critical Quality Attributes are associated with the drug substance, excipients, intermediates and drug product. Critical Quality attributes covers the properties that impart the desired quality, safety, and efficacy. In context of biotechnological products, CQAs are typically those aspects which affect product purity and stability. Drug product CQAs can be identified from the Target product profile. The use of strong risk assessment methods for identification of CQAs is new to the QbD standard $[6,10]$.

\section{Critical Process Parameters (CPPS)}

Critical process parameters (CPPs) are defined as "parameters whose variability have an impact on a CQA and therefore should be monitored or controlled to ensure the process produces the desired quality" Process robustness is the ability of a process to demonstrate acceptable quality and performance and tolerate variability in inputs at the same time. To demonstrate the reproducibility and consistency of a process, process capability should be studied (Figures 3 \& 4). Process capability is a statistical measure of the inherent process variability for a given characteristics. The most widely accepted formula for process capability is six-sigma [11]. Process capability index is the value of the tolerance specified for a particular characteristic divided by the process capability, which is defined as follows:

$$
\text { Process capability index }(\mathrm{CpK})=\frac{\text { Upper limit of specification }- \text { Lower limit of specification }}{6-\text { Standard deviation }}
$$

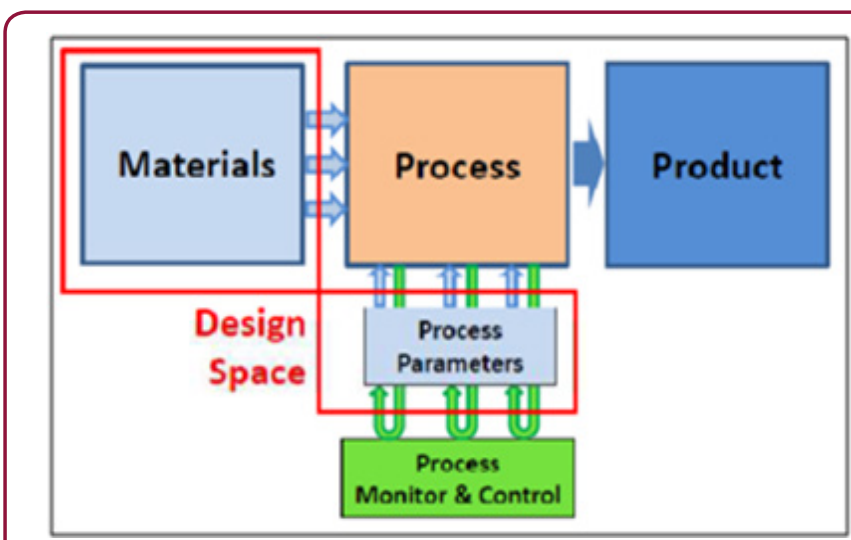

Figure 3: Design Space [15].

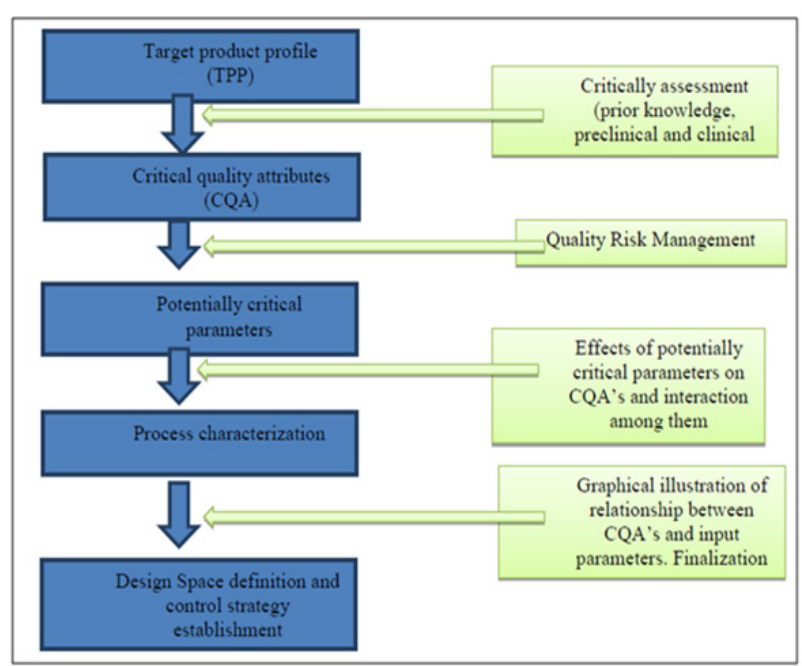

Figure 4: Flow Chart of Quality by Design [18].

If the $\mathrm{CpK}$ is significantly greater than one, the process is defined capable. But if the process capability is low, there are five step procedures to progressively reduce the variability of the process. These five steps are:

I. Define: The intended improvement should be clearly stated

II. Measure: The critical product performance attributes should be measured to see if they are out of specification and used to the sigma level of the process.

III. Analyze: When the sigma level is below the target, steps should be taken to increase it, starting by identifying the most significant causes of the excessive variability.

IV. Improve: The process should be redesigned and/ or process controls should be incorporated to eliminate or attenuate the significant toot causes of variance. 
V. Control: The improved manufacturing process should be evaluated and maintained.

\section{Risk Assessment}

Risk assessment is the linkages between material attributes $\&$ process parameters. It is performed during the lifecycle of the product to identify the critical material attributes \& critical process parameters. A material attributes can be an excipients raw material, drug substances, reagents, solvents, packaging \& labelling materials. A material attributes can be quantified \& typically fixed but sometimes can be changed during further processing [12].

E.g. Impurity profile, porosity, specific volume, sterility.

\section{Design of Experiment}

Design of experiments (DOE) is a systematic method to determine the relationship between factors affecting a process and the output of that process. In other words, it is used to find causeand-effect relationships. This information is needed to manage process inputs in order to optimize the output. An understanding of DOE first requires knowledge of some statistical tools and experimentation concepts. Although a DOE can be analyzed in many software programs, it is important for practitioners to understand basic DOE concepts for proper application.[vii] For example parameters that affect the coating process are given in (Figure 5) $[13,14]$. Critical parameters are considered as independent variables in DOE.

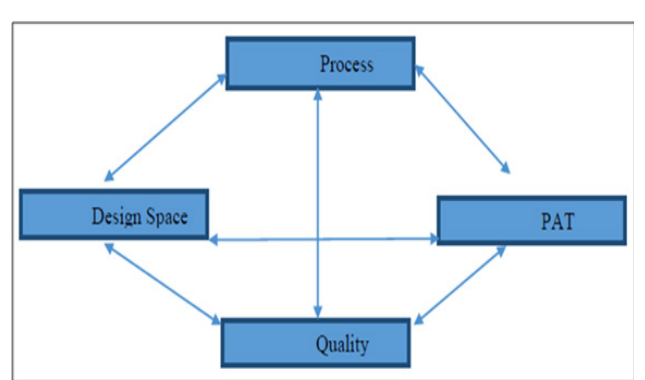

Figure 5: Interrelationships between PAT and QbD [19].

\section{Design Space}

ICH Q8 (R2) defines Design space as, the multidimensional combination and interaction of input variables (e.g. material attributes) and process parameters that have been demonstrated for provide assurance of quality. It will Working within the Design space is not be considered as a change, Movement out of the Design space it is considered to be a change and would normally initiate a regulatory post-approval change process. Design space is proposed by the applicant and is subject to regulatory assessment and approval. Thus Design space is potentially scale and equipment dependent, the Design space determined at the laboratory scale may not be relevant to the process at the commercial scale $[14,15]$.

\section{PROCESS ANALYTICAL TECHNOLOGY}

The concept originates from the desire of the regulators to shift control of product quality towards a science-based approach that explicitly attempts to reduce the risk to patients by controlling the manufacturing based on understanding of the process $[16,17]$.
From a PAT standpoint, a process is considered well understood when:

a. All critical sources of variability are identified and explained;

b. Variability is managed by the process; and

c. Product quality attributes can be accurately and reliably predicted.

PAT has been defined as "A system for designing, analyzing, and controlling manufacturing through measurements, during processing of critical quality and performance attributes of raw and in-process materials and processes, with the goal of ensuring final product quality". The goal of PAT is to "enhance understanding and control the manufacturing process, which is consistent with our current drug quality system: quality cannot be tested into products; it should be built-in or should be by design."

\section{Conclusion}

Quality has become an important issue in today's era. Everyone talks on quality but building quality is not mere task. It needs a long process for fulfilment of the required quality attributes in the material. When the term Quality is defined in context of Pharma, it becomes a legal issue. There are numerous guidelines and governing bodies who imply "should be and should not be conditions". Quality by Design and Process analytical technology has been emerging concepts for developing the required quality attributes in the product at its design stage which saves time, energy and also reduces market recall of the products.

\section{References}

1. Rathore AS, Winkle H (2009) Quality by design for biopharmaceuticals. Nat Biotechnol 27(1):26-34.

2. (2009) US Food and Drug Administration. Guidance for industry Q8 (R2) pharmaceutical development. US Department of Health and Human Service (FDA, Rockville, MD).

3. Jadhav JB, Girawale NN, Chaudhary RA (2014) Quality by Design (QBD) Approach used in Development of Pharmaceuticals. Int J Pure App Biosci 2(5): 214-233.

4. Nagar M, Panwar KS, Chopra VS, Bala I, Trivedi P (2010) Quality by design: A systematic approach to pharmaceutical development Der Pharmacia Lettre 2(2): 111-130.

5. Lan Z, Shirui M (2017) Application of quality by design in the current drug development. Asian journal of pharmaceutical sciences 12(1): 1-8.

6. Rane S, Bhat D (2011) Q bD approach to analytical RP HPLC method development and its validation. International journal of Pharmacy and Pharmaceutical Sciences. 3(1): 179-187.

7. Sushila D, Nayana VP, Amruta SK, Gaikwad PS (2015) Quality by Design. JPQA 1(2):18-24.

8. Gupta A, Fuloria NK (2012) Short review on Quality by Design: A new era of Pharmaceutical Drug Development. Int J Drug Dev \& Res 4(3): 19-26.

9. Lionberger RA, Lee SA, Lee LM, Raw A, Yu LX (2008) Quality by Design: Concepts for ANDAs. The APPS Journal 10(2): 268-276.

10. (2007) US Food and Drug Administration (FDA) Department of Health and Human Services, Pharmaceutical Quality for the 21st Century a Risk-Based Approach Progress Report. 
11. Juran JM (1992) Quality by design the new steps for planing quality into goods and services, Revised Edition, free press, new York, USA, p.1-2.

12. Nishendu P (2012) A complete review of Quality by Design. Int J Pharm Sci Rev Res 17(2): 20-28

13. Nadpara NP, Thumar RV, Kalola VN, Patel PB (2012) Quality By Design (Qbd) : A Complete Review. Int J Pharm Sci Rev Res 17(2): 20-28.

14. (2014) ICH Q9: Quality Risk Management-an update.

15. Patil AS, Pethe AM (2013) Quality by Design (QbD): A new concept for development of quality pharmaceuticals, IJPQA 4(2): 13-19.
16. Roy S (2012) Quality by design: A holistic concept of building quality in pharmaceuticals. Int J Pharm Biomed Res 3(2): 100-108.

17. Jain S (2014) Quality By Design (Qbd): A Comprehensive Understanding Of Implementation And Challenges In Pharmaceuticals Development. Int J Pharm Pharm Sci 6(1): 29-35.

18. Kumar N (2015) A Review on quality by design approach (QBD) for Pharmaceuticals. Int J Drug Dev \& Res 7(2): 35-44.

19. Tambe K, Bonde S (2017) A review on: Applications of pharmaceutical quality by design in product development. World J Pharm Sci 5(1): 5870.

$\begin{array}{ll}\text { BIOMEDICAL } & \text { Assets of Publishing with us } \\ \text { RESEARCHES } & \text { Global archiving of articles } \\ & \text { - Immediate, unrestricted online access } \\ & \text { - Rigorous Peer Review Process } \\ & \end{array}$

